\title{
Occurrence and antibiotic resistance of Salmonella spp. in raw beef from wet market and hypermarket in Malaysia
}

\author{
${ }^{1 *}$ Tan, C.W., ${ }^{1}$ Noor Hazirah, M.Z., ${ }^{1}$ Shu'aibu, I., ${ }^{1}$ New, C.Y., ${ }^{1}$ Malcolm, T.T.H., ${ }^{1}$ Thung, \\ T.Y., ${ }^{3}$ Lee, E., ${ }^{3}$ Wendy, R.D. ${ }^{1,3}$ Nuzul, N.J., ${ }^{2,3}$ Noor Azira, A.M., ${ }^{2}$ Ungku Fatimah, U.Z.A., \\ ${ }^{1,4}$ Rukayadi, Y., ${ }^{4}$ Rinai, R. and ${ }^{1,3}$ Son, R. \\ ${ }^{1}$ Department of Food Science, Faculty of Food Science and Technology, Universiti Putra Malaysia, 43400 \\ UPM Serdang, Selangor Darul Ehsan, Malaysia \\ ${ }^{2}$ Department of Food Service and Management, Faculty of Food Science and Technology, Universiti Putra \\ Malaysia, 43400 UPM Serdang, Serdang, Selangor Darul Ehsan, Malaysia \\ ${ }^{3}$ Food Safety and Food Integrity, Institute of Tropical Agriculture and Food Security (ITAFoS), Universiti \\ Putra Malaysia, 43400 UPM Serdang, Selangor Darul Ehsan, Malaysia \\ ${ }^{4}$ Institute of Bioscience, Universiti Putra Malaysia, 43400 UPM Serdang, Selangor Darul Ehsan, Malaysia
}

Article history:

Received: 2 June 2018

Received in revised form: 17 July 2018

Accepted: 21 July 2018

Available Online: 25 July 2018

\section{Keywords:}

Salmonella,

Prevalence,

Raw meat,

MPN,

PCR,

Antibiotic susceptibility test

DOI:

https://doi.org/10.26656/fr.2017.3(1).202

\begin{abstract}
Salmonellae are highly pathogenic foodborne bacteria able to cause infection even at low doses. Infection by Salmonella from contaminated foods leads to gastrointestinal disease known as salmonellosis. Raw beef can be a source of human infection if the meat products are not properly handled, stored or cooked. This study aimed to investigate the prevalence and concentration of Salmonella in the raw beef sold at wet markets and hypermarkets in Serdang, Selangor, Malaysia, using MPN-PCR and MPN-plating on Xylose Lysine Deoxycholate (XLD) medium. In addition, Salmonella isolates recovered from the samples were tested for antibiotics susceptibility using Kirby-Bauer antibiotic susceptibility testing. The incidence of Salmonella in the raw beef samples using plating and PCR methods were $64.63 \%(53 / 82)$ and $17.07 \%$ (14/82) respectively. The microbial concentration of Salmonella in raw beef samples ranged between 3-4600 MPN/g by MPNplating and 3-30 MPN/g by MPN-PCR approach. All isolates were found to be susceptible to imipenem, gentamicin, kanamycin, and chloramphenicol but resistant to cephalothin. It can be deduced from the results that raw beef can be a reservoir for Salmonella infection and the use of cephalothin $(30 \mu \mathrm{g})$ in the treatment of infection due to these strains could be ineffective. Preventive measures such as proper temperature control as well as proper handling of raw beef in the market place are crucial to the minimization of any potential health hazard posed by this foodborne pathogen.
\end{abstract}

\section{Introduction}

Salmonellae are rod-like Gram-negative bacteria that cause salmonellosis, one of the most important foodborne illnesses worldwide. Salmonella is described as highly pathogenic bacteria as their infective dose is as low as 108 to $10^{4}$ cells (Perreten, 2005). Salmonellosis is a self-limiting infection that does not normally require antibiotic medication. However, when the disease worsens, antibiotic therapy could be recommended for the patient (CDC, 2017). In Malaysia, Salmonellae have been recognized as the culprits for some of the food poisoning outbreaks (ISID, 2013; Karim et al., 2017). Outbreaks of food poisoning are probably due to crosscontamination, improper handling, inappropriate storage temperature and inadequate cooking which encourage the growth of these pathogens in food.

Meat contributes an important proportion in the human diet. It is classified into red and white meat depending on the concentration of myoglobin, a substance in the muscle fiber of animals that is responsible for the meat color. Oxymyoglobins are meat components responsible for the red color of animal flesh and are developed upon exposure of myoglobin to oxygen (Mancini and Hunt, 2005). However, the redness of flesh also depends on the animal species, ages, and fiber types. Generally, cow, sheep, buffalo, goat, pork, and horses are categorized as red meat animals. 
Data on prevalence and outbreak involving Salmonella reported were usually those associated with poultry, meat, eggs and dairy product (Dominguez et al., 2009; Gantois et al., 2009; Minami et al., 2010; Chong et al., 2017). The innermost part of the meat of animals is considered sterile unless the animal is infected with pathogens. The contamination of meat by pathogenic microbes is likely due to cross-contamination at various processing steps in the slaughterhouse and marketplace, transportation of the meat, poor packaging and after cooking.

Antibiotics are widely used in the animal farm to treat, prevent and control infections and promote growth (Marshall and Levy, 2011). The excessive use and misuse of antibiotics in livestock are among the public health concerns as the antibiotic residues could be passed along the food chain which eventually makes the bacteria in the food chain resistant to them. Animals are the main reservoir for many zoonotic pathogens and the extensive use of antibiotics as growth promoters as well as therapeutic agents in the animal farm can promote the evolution of antibiotic-resistant strains. For instance, several food animals such as poultry and cattle have been reported to serve as reservoirs for multidrug-resistant Salmonellae (Yoke-Kqueen et al., 2008; Arslan and Eyi, 2010; Thung et al., 2016).

The purpose of this study was to determine the occurrence of Salmonella in raw beef samples obtained from various wet markets and hypermarkets in Serdang, Selangor, Malaysia using MPN-Plating and MPN-PCR. Antibiotic susceptibility testing was performed on the isolates recovered from the raw beef samples to determine their tendencies for multiple antibiotic resistance.

\section{Materials and methods}

\subsection{Sample collection}

A total of eighty-two beef samples were purchased from different wet markets $(n=41)$ and hypermarkets $(n=41)$ in Serdang, Selangor, Malaysia. All samples were collected in a sterile plastic bag, placed into a cold storage box with ice packs and transported to the laboratory. Samples were analysed immediately upon arrival to the laboratory.

\subsection{Sample processing}

Each sample was processed individually on a sterilized cutting board. Beef samples were cut and weighed approximately $10 \mathrm{~g}$ into a stomacher bag and added with $90 \mathrm{~mL}$ of buffered peptone water (BPW; Oxoid, UK). The mixture was then homogenized for $60 \mathrm{~s}$ using a Stomacher Lab-Blender 400 (Seward Medical,
UK).

\subsection{Enumeration of Salmonella using the Most Probable Number (MPN) method}

The homogenized sample in the stomacher bag $\left(10^{-1}\right.$ dilution) was serially diluted by transferring $1 \mathrm{~mL}$ into a tube containing $9 \mathrm{~mL}$ of BPW to make a $10^{-2}$ dilution and this action continued until $10^{-4}$ dilution was reached. Each dilution was then transferred into a set of 3-tubes MPN. The MPN tubes were incubated at $37^{\circ} \mathrm{C}$ overnight. Following the incubation, MPN tubes were examined for growth and turbidity and proceeded for confirmation on plating and PCR.

\subsubsection{MPN-plating}

Positive MPN tubes were confirmed by streaking on Xylose Lysine Deoxycholate (XLD; Oxoid, UK) agar plates. The agar plates were incubated at $37^{\circ} \mathrm{C}$ overnight. Agar plates yielding presumptive Salmonella colonies (black centers) were confirmed positive. The presumptive colonies were picked from each agar plate and streaked on Tryptic Soy Agar (TSA; Oxoid, UK) for purification and later stored as working culture.

\subsubsection{MPN-PCR}

DNA extraction was carried out using boiled cell method (Pui et al., 2011). From the positive MPN tubes, $1 \mathrm{~mL}$ was transferred into a $1.5 \mathrm{~mL}$ microcentrifuge tube. The suspension was centrifuged at $12,000 \mathrm{x} g$ for 3 mins. The supernatant was discarded, and the pellet was re-suspended in $500 \mu \mathrm{L}$ of sterile distilled water. The suspension in the tube was heated on a hot dry bath (Labnet, USA) at $100^{\circ} \mathrm{C}$ for $10 \mathrm{mins}$ and then cooled immediately at $-20^{\circ} \mathrm{C}$ for another 10 mins. The suspension was centrifuged at $12,000 \mathrm{x} g$ for $1 \mathrm{~min}$ prior to use. The supernatant was used as the DNA template.

PCR detection of Salmonella in raw beef samples was performed using a pair of primer (SIGMA, USA) with the forward sequence of 5'-ATC GCT GAC TTA TGC AAT CG-3' and reverse sequence of 5'- CGG GTT GCG TTA TAG GTC TG-3' specifically designed to amplify a $204 \mathrm{bp}$ fragment of $о т p C$ genes in the Salmonella spp. (Kwang et al., 1996).

A total of $25 \mu \mathrm{L}$ reaction mixture was prepared for the amplification and consisted of $7.5 \mu \mathrm{L}$ of $5 \times \mathrm{PCR}$ buffer, $2.0 \mu \mathrm{L}$ of $25 \mathrm{mM} \mathrm{MgCl}_{2}, 0.5 \mu \mathrm{L}$ of $10 \mathrm{mM}$ dNTPs, $0.25 \mu \mathrm{L}$ of $10 \mu \mathrm{M}$ ompC primers, $1.5 \mathrm{U}$ of Taq polymerase, $2 \mu \mathrm{L}$ of DNA template and finally made up to $25 \mu \mathrm{L}$ with sterile distilled water. PCR was carried out in the thermocycler, GeneAmp ${ }^{\circledR}$ PCR System 2700 (Applied Biosystem,USA) with the following conditions: initial denaturation at $95^{\circ} \mathrm{C}$ for 3 mins, 35 cycles each of 
denaturation at $95^{\circ} \mathrm{C}$ for $1 \mathrm{~min}$, annealing at $56^{\circ} \mathrm{C}$ for 1 min, extension at $72^{\circ} \mathrm{C}$ for $1 \mathrm{~min}$, and a final extension at $72^{\circ} \mathrm{C}$ for 7 mins. In order to visualize the PCR products, $5 \mu \mathrm{L}$ of the PCR products were loaded onto an ethidium bromide-stained $1.2 \%$ agarose gel prepared using $0.5 \times$ TBE buffer. The products were subjected to gel electrophoresis at $100 \mathrm{~V}$ for $30 \mathrm{mins}$ and viewed under the UV-transilluminator using gel documentation system (SynGene, UK).

\subsection{Antibiotic susceptibility testing}

Antibiotic susceptibility testing was conducted on the confirmed isolates of Salmonella from the samples by Kirby-Bauer method (Bauer et al., 1966). Salmonella isolates kept in the stock culture were subcultured aerobically in Muller Hinton broth (MHB; Oxoid, UK) at $37^{\circ} \mathrm{C}$ for overnight. The cultures were swabbed evenly onto Mullen Hinton agar (MHA; Oxoid, UK) plate and left to dry for 5 mins. Antibiotic disks were pressed down lightly to ensure attachment on the agar surface. The plates were incubated in inverted positions at $37^{\circ} \mathrm{C}$ for $24 \mathrm{~h}$. A total of twelve types of antibiotic susceptibility test disks, namely imipenem $(10 \mu \mathrm{g})$, nalidixic acid $(30 \mu \mathrm{g})$, cephalothin $(30 \mu \mathrm{g})$, ciprofloxacin (5 $\mu \mathrm{g})$, ceftriaxone $(5 \mu \mathrm{g})$, sulphamethoxazole/ trimethoprim $(25 \mu \mathrm{g})$, tetracycline $(30 \mu \mathrm{g})$, ceftazidime $(30 \mu \mathrm{g})$, gentamicin $(10 \mu \mathrm{g})$, streptomycin $(10 \mu \mathrm{g})$, chloramphenicol $(30 \mu \mathrm{g})$, and kanamycin $(30 \mu \mathrm{g})$ were used in this study. After incubation, the diameter of the inhibition zone was measured to the nearest whole millimetre. Antibiotic susceptibility profiles of the isolates were determined based on the Clinical and Laboratory Standards Institute (CLSI) guidelines. The value of multiple antibiotic resistance (MAR) index was calculated using the formula, $a / b$, where ' $a$ ' is the number of antibiotics to which the particular isolate was resistant and ' $b$ ' is the total number of antibiotics tested (Krumperman, 1983).

\section{Results}

\subsection{Occurrence of Salmonella in raw beef}

The occurrence of Salmonella in raw beef obtained from the hypermarkets and wet markets are shown in Table 1. The enumeration of Salmonella in the raw beef samples through the MPN-plating showed a higher prevalence $(64.63 \%)$ compared to the MPN-PCR $(17.07 \%)$ approach. In the case of Salmonella concentration in the raw beef samples, the MPN-plating also showed a higher concentration of presumptive Salmonella in the samples (ranging from 3 to 4600 $\mathrm{MPN} / \mathrm{g}$ ) than the MPN-PCR method with a range of 3 to $30 \mathrm{MPN} / \mathrm{g}$.

The MPN-PCR results revealed that $9.76 \%(4 / 41)$ of the samples from the hypermarkets and $24.39 \%(10 / 41)$ of the samples from the wet markets were found to harbour Salmonella with the microbial load of 3-30 $\mathrm{MPN} / \mathrm{g}$ and 3-9.2 MPN/g respectively. The prevalence and concentration of Salmonella in the raw beef samples obtained from the wet markets were found to be significantly lower $(P<0.05)$ than those from the hypermarkets.

\subsection{Antibiotic susceptibility test}

Four confirmed Salmonella isolates were recovered from the samples and tested for antibiotic susceptibility test. Antibiotic susceptibility profiles of Salmonella isolates from raw beef samples are shown in Table 2. All the four $(100 \%)$ isolates were susceptible to imipenem, gentamicin, kanamycin, and chloramphenicol. About $75 \%$ of the isolates were susceptible to ceftriaxone and ciprofloxacin. Half $(50 \%)$ of the isolates were susceptible to nalidixic acid, sulphamethoxazole/ trimethoprim, tetracycline, ceftazidime, and streptomycin. However, $25 \%$ of the isolates showed intermediate resistance to nalidixic acid, ciprofloxacin, ceftazidime, and streptomycin and all the isolates were resistant to cephalothin. In addition, $50 \%$ of the isolates were resistant to both of sulphamethoxazole / trimethoprim and tetracycline and $25 \%$ resistant to nalidixic acid, ceftriaxone, ceftazidime, and streptomycin. All isolates showed resistance to at least two antibiotics used in this study. Multiple antimicrobial resistance (MAR) index values of the isolates are displayed in Table 3. Isolate A had a MAR index value of less than 0.2. Isolate $\mathrm{B}, \mathrm{C}$ and $\mathrm{D}$ displayed multiple antibiotics resistance with MAR index values of 0.25 , 0.25 and 0.33 , respectively.

\section{Discussion}

The study of the prevalence of Salmonella in raw beef samples by MPN-plating on XLD agar recorded a higher level of detection rate and microbial concentration (MPN/g) than the MPN-PCR approach. The higher

Table 1. Occurrence of Salmonella in raw beef

\begin{tabular}{lcccc}
\hline \multirow{2}{*}{ Location } & \multicolumn{2}{c}{ MPN-Plating } & \multicolumn{2}{c}{ MPN-PCR } \\
\cline { 2 - 5 } & Prevalence, $\mathrm{n}(\%)$ & Concentration Range (MPN/g) & Prevalence, $\mathrm{n}(\%)$ & Concentration Range (MPN/g) \\
\hline Hypermarket & $21 / 41(58.54)$ & $3-4600$ & $4 / 41(9.76)$ & $3-30$ \\
Wet Market & $28 / 41(68.29)$ & $3-4600$ & $10 / 41(24.39)$ & $3-9.2$ \\
Overall & $53 / 82(64.63)$ & $3-4600$ & $14 / 82(17.07)$ & $3-30$ \\
\hline
\end{tabular}


Table 2. Antibiotic susceptibility profiles of Salmonella isolates from the raw beef samples

\begin{tabular}{llccc}
\hline \multicolumn{1}{c}{ Class of antibiotics } & \multicolumn{1}{c}{ Antibiotics } & Resistant (\%) & Intermediate (\%) & Susceptible (\%) \\
\hline Carbapenem & Imipenem $(10 \mu \mathrm{g})$ & - & - & $4(100 \%)$ \\
Quinolone & Nalidixic acid $(30 \mu \mathrm{g})$ & $1(25 \%)$ & $1(25 \%)$ & $2(50 \%)$ \\
Cephalosporin I & Cephalothin $(30 \mu \mathrm{g})$ & $4(100 \%)$ & - & - \\
Fluoroquinolone & Ciprofloxacin $(5 \mu \mathrm{g})$ & - & $1(25 \%)$ & $3(75 \%)$ \\
Cephalosporin III & Ceftriaxone $(5 \mu \mathrm{g})$ & $1(25 \%)$ & - & $3(75 \%)$ \\
Folate pathway & Sulphamethoxazole/ trimethoprim $(25 \mu \mathrm{g})$ & $2(50 \%)$ & - & $2(50 \%)$ \\
inhibitor & Tetracycline $(30 \mu \mathrm{g})$ & $2(50 \%)$ & - & $2(50 \%)$ \\
Tetracyclines & Ceftazidime $(30 \mu \mathrm{g})$ & $1(25 \%)$ & $1(25 \%)$ & $2(50 \%)$ \\
Cephalosporin III & Gentamicin $(10 \mu \mathrm{g})$ & - & - & $4(100 \%)$ \\
Aminoglycosides & Streptomycin $(10 \mu \mathrm{g})$ & $1(25 \%)$ & $1(25 \%)$ & $2(50 \%)$ \\
Aminoglycosides & Chloramphenicol $(30 \mu \mathrm{g})$ & - & - & $4(100 \%)$ \\
Phenicols & Kanamycin $(30 \mu \mathrm{g})$ & - & - & $4(100 \%)$ \\
Aminoglycosides & & & & \\
\hline
\end{tabular}

Table 3. Multiple antimicrobial resistance (MAR) index value of Salmonella isolates.

\begin{tabular}{cccc}
\hline Isolate & $\begin{array}{c}\text { No of antibiotic } \\
\text { resistance }\end{array}$ & Type of antibiotic resistance & MAR index \\
\hline A & 2 & Sulphamethoxazole/ trimethoprim, cephalothin & 0.17 \\
B & 3 & Sulphamethoxazole/ trimethoprim, tetracycline, cephalothin & 0.25 \\
C & 3 & Streptomycin, nalidixic acid, cephalothin & 0.25 \\
D & 4 & Ceftriaxone, tetracycline, ceftazidime, cephalothin & 0.33 \\
\hline
\end{tabular}

number of Salmonella as determined by MPN-plating may indicate a high number of false-positive presumptive colonies that were morphologically similar as true-positive Salmonella colonies on XLD agar. The results obtained from the MPN-PCR were therefore considered more reliable and accurate than MPN-plating in detecting Salmonella from the raw beef sample. Similarly, Pui et al. (2011) reported that MPN-PCR had higher sensitivity in detecting Salmonella from sliced fruits than MPN-plating method. This was further supported by the report of Maks and Fu (2013), in which the PCR approach had significantly better detection of Salmonella with fewer false-negative results than the bacteriological medium.

Several studies have also found out that the low specificity of XLD medium created a high number of false positive identification of Salmonella species (Rall et al., 2005; Hyeon et al., 2012; Yhiler et al., 2015). Rall et al. (2005) stated that XLD allows the growth of selective bacteria with Salmonella, Proteus, and Citrobacter that displayed similar characteristics as negative lactose fermentation and negative hydrogen sulfide $\left(\mathrm{H}_{2} \mathrm{~S}\right)$ production on this classical medium. Thus, the colonies of Proteus and Citrobacter probably appear and identified as presumptive Salmonella colony on XLD medium. In addition, Hyeon et al. (2012) and Yhiler et al. (2015) concluded that XLD medium had high sensitivity but with low specificity for the detection of Salmonella.
The results of the MPN-PCR recorded the overall prevalence of Salmonella in the raw beef samples of 17.07\%. Comparatively, Thung et al. (2017) reported $7.5 \%$ of raw beef samples obtained from the retail markets in Selangor Malaysia, positive for Salmonella with the microbial load of $<3$ to $15 \mathrm{MPN} / \mathrm{g}$. Similarly, Chong et al. (2017) also reported $10 \%$ of beef carcasses collected from the local abattoirs in Selangor, Malaysia as positive for Salmonella. Modarressi and Thong (2011) reported that $27.2 \%$ of raw beef samples purchased from the retail markets in Kuala Lumpur, Malaysia were contaminated with Salmonella. In other countries, the occurrence of Salmonella in the raw beef sample collected from the retail markets in Vietnam was reported to be 39.9 to $48.6 \%$ (Phan et al., 2005; Thai et al., 2012).

Moreover, the occurrence of Salmonella in the wet market samples was found to be higher than in the hypermarket samples. This finding was similar to the results reported by Shafini et al. (2017) in Malaysia. Shafini et al. (2017) found out that $20.8 \%, 14.8 \%$ and $11.1 \%$ of the beef samples from the wet markets, hypermarkets, and butcher shops respectively were contaminated with Salmonella. This corresponds with a finding in China in which Yang et al., (2011) reported the prevalence of Salmonella on raw poultry with higher prevalence in the wet markets $(54.4 \%)$ than in large markets $(50.3 \%)$ and small markets $(52.1 \%)$. The reason for the higher incidence of Salmonella in samples 
obtained from the wet markets than those from hypermarket could be due to inadequate food safety practices compared to the food safety measures and sanitation programmes implemented in the hypermarkets. Thung et al. (2016) mentioned that hypermarket workers generally practice good personal hygiene and sanitation in the food processing environment than those of the wet markets.

The microbial load of Salmonella from the wet market and hypermarket samples were 3-9.2 MPN/g and 3-30 MPN/g, respectively. The concentration of Salmonella in the hypermarket samples was found to be slightly higher than that of the samples from the wet market. This finding was in contrast with the study of Thung et al. (2016), who reported the microbial load of Salmonella in beef samples from the wet market with a higher concentration ( $<3$ to $15 \mathrm{MPN} / \mathrm{g}$ ) than supermarket samples $(<3$ to $3.6 \mathrm{MPN} / \mathrm{g})$. The higher Salmonella concentration in the hypermarket samples might be due to the longer operating hours than in wet markets, in which the meat exposed to the environment and temperature abuse longer which facilitates bacterial multiplication. Conversely, many wet markets operation hours are usually half a day eventually providing quality fresh produce for the consumers.

The existence of multiple antibiotic resistant bacteria can lead to human infections and probably creates challenges for the treatment of Salmonella infections in humans and animals (Thung et al., 2016). The use of antibiotics for treatment and as growth promoters in farm animals may promote the emergence and spread of antibiotic-resistant microorganisms to the human population (Khoo et al., 2015). Bacterial isolate is classified as multiple antibiotic resistant if the MAR value is higher than 0.2 . Three isolates were found with a MAR value of higher than 0.2 and more than $50 \%(2 / 4)$ of Salmonella isolates were resistant to cephalothin, sulphamethoxazole/ trimethoprim, and tetracycline in this study. Another study reported that Salmonella isolated from the raw beef, chicken meat, and street foods exhibited the highest resistance to tetracycline (73.8\%), followed by sulfonamide (63.6\%) and streptomycin (57.9\%) (Thong and Modarressi, 2011). Minami et al. (2010) stated that most of the Salmonella isolated showed resistance to sulfisoxazole, tetracycline, and streptomycin. Yoke-Kqueen et al. (2008) reported that Salmonella isolated from the indigenous vegetables and poultry exhibited multidrug resistance to erythromycin, tetracycline, streptomycin and trimethoprim/sulfamethoxazole.

\section{Conclusion}

MPN-PCR was more reliable than MPN-plating with regards to the degree of specificity of identification of Salmonella species in raw beef samples. Using MPNplating method, $64.63 \%$ of the samples were detected with Salmonella with a concentration range of 3-4600 MPN/g in comparison to $17.07 \%$ of the samples detected with a concentration range of 3-30 MPN/g via MPNPCR approach. Raw beef can become a common vehicle for Salmonella transmission and if inadequate practice of food hygiene and sanitation, Salmonella infection is possible. Multiple antibiotic resistant Salmonella should be regarded as an issue and the spread should be viewed as a challenge to combat the bacteria and conserving public health.

\section{Conflict of Interest}

The authors declare no conflict of interest.

\section{Acknowledgement}

Research fund was granted by the Universiti Putra Malaysia with Grant number GP-IPS 2015 (GPIPS/2015/9466100).

\section{References}

Arslan, S. and Eyi, A. (2010). Occurrence and antimicrobial resistance profiles of Salmonella species in retail meat products. Journal of Food Protection, 73(9), 1613-1617. https:// doi.org/10.4315/0362-028X-73.9.1613

Bauer, A.W., Kirby, W.M., Sherris, J.C. and Turck, M. (1966). Antibiotic susceptibility testing by a standardized single disk method. American Journal of Clinical Pathology, 45(4), 493-496. https:// doi.org/10.1093/ajcp/45.4_ts.493

Centre for Disease Control and Prevention (CDC). (2017). Salmonella. Retrieved November 11, 2017 from CDC website: https://www.cdc.gov/salmonella/ index.html

Chong, E.S., Bidin, Z.F., Bakar, N.F.A. and Zulfakar, S.S. (2017). Bacterial contamination on beef carcass at selected abattoirs located in Selangor, Malaysia. Malaysian Applied Biology, 46(1), 37-43.

Dominguez, M., Jourdan-Da Silva, N., Vaillant, V., Pihier, N., Kermin, C., Weill, F.X., Delmas, G., Brisabois, A. and de Valk, H. (2009). Outbreak of Salmonella enterica serotype Montevideo infections in France linked to consumption of cheese made from raw milk. Foodborne Pathogens and Disease, 6 (1), 121-128. https://doi.org/10.1089/fpd.2008.0086

Gantois, I., Ducatelle, R., Pasmans, F., Haesebrouck, F., 
Gast, R., Humphrey, T.J. and Van Immerseel, F. (2009). Mechanisms of egg contamination by Salmonella Enteritidis. FEMS Microbiology Reviews, 33(4), 718-73. https://doi.org/10.1111/ j.1574-6976.2008.00161.x

Hyeon, J.Y., Park, J.H., Chon, J.W., Wee, S.H., Moon, J.S., Kim, Y.J. and Seo, K.H. (2012). Evaluation of selective enrichment broths and chromogenic medium for Salmonella detection in highly contaminated chicken carcasses. Poultry Science, 91 (5), 1222-1226. https://doi.org/10.3382/ps.201101936

International Society for Infectious Diseases (ISID). (2013). Salmonellosis - Malaysia: (Kedah), Wedding Banquet, Fatal. Retrieved April 25, 2018 from ProMED-mail website: http:// www.promedmail.org/direct.php? id $=20131008.1989195$

Karim, B.A., Latip, A.L., Shukor, A.S.A., Rashid, N.A., Mohd, W.M.W. and Kamaludin, F. (2017). A large common source outbreak of Salmonella Typhimurium linked to Kuala Terengganu night markets, Malaysia, 2014. Outbreak, Surveillance and Investigation Reports 10(2), $1-7$.

Khoo, E., Roseliza, R., Khoo, L., Nafizah, M., Saifu Nazri, R., Hasnah, Y., Norazariyah, M., Rosnah, Y., Rosna, D., Siti, N.H.R. and Ramlan, M. (2015). Antimicrobial resistance of Salmonella enterica serovar Typhimurium from various meats received in VRI. Malaysian Journal of Veterinary Research, 6, 61-65.

Krumperman, P.H. (1983). Multiple antibiotic resistance indexing of Escherichia coli to identify high-risk sources of fecal contamination of foods. Applied and Environmental Microbiology, 46(1), 165-170.

Kwang, J., Littledike, E.T. and Keen, J.E. (1996). Use of the polymerase chain reaction for Salmonella detection. Letters of Applied Microbiology, 22(1), 46 -51 . https://doi.org/10.1111/j.1472765X.1996.tb01106.x

Maks, N. and Fu, T.J. (2013). Evaluation of PCR detection of Salmonella in alfalfa sprouts and spent irrigation water collected during sprouting of naturally contaminated seed. Journal of Food Protection, 76(2), 314-317. https:// doi.org/10.4315/0362-028X.JFP-12-155

Mancini, R.A. and Hunt, M. (2005). Current research in meat color. Meat science, 71(1), 100-121. https:// doi.org/10.1016/j.meatsci.2005.03.003

Marshall, B.M. and Levy, S.B. (2011). Food animals and antimicrobials: impacts on human health. Clinical Microbiology Reviews, 24(4), 718-733. https://

\section{doi.org/10.1128/CMR.00002-11}

Minami, A., Chaicumpa, W., Chongsa-Nguan, M., Samosornsuk, S., Monden, S., Takeshi, K., Makino, S. and Kawamoto, K. (2010). Prevalence of foodborne pathogens in open markets and supermarkets in Thailand. Food Control, 21(3), 221226. https://doi.org/10.1016/j.foodcont.2009.05.011

Modarressi, S. and Thong, K.L. (2011). Isolation and molecular sub typing of Salmonella enterica from chicken, beef and street foods in Malaysia. Scientific Research and Essays, 5(18), 2713-2720.

Perreten, V. (2005). Resistance in the food chain and in bacteria from animals: relevance to human infections. In White, D.G., Alekshun, M.N. and McDermott, P.F. (Eds). Frontiers in Antimicrobial Resistance: A Tribute to Stuart B. Levy, p. 446-464. Washington, DC: American Society of Microbiology. https:// doi.org/10.1128/9781555817572.ch34

Phan, T.T., Khai, L.T.L., Ogasawara, N., Tam, N.T., Okatani, A.T., Akiba, M. and Hayashidani, H. (2005). Contamination of Salmonella in retail meats and shrimps in the Mekong Delta, Vietnam. Journal of Food Protection, 68(5), 1077-1080. https:// doi.org/10.4315/0362-028X-68.5.1077

Pui, C.F., Wong, W.C., Chai, L.C., Nillian, E., Ghazali, F.M., Cheah, Y.K., Nakaguchi, Y., Nishibuchi, M. and Son, R. (2011). Simultaneous detection of Salmonella spp., Salmonella Typhi and Salmonella Typhimurium in sliced fruits using multiplex PCR. Food Control, 22(2), 337-342. https:// doi.org/10.1016/j.foodcont.2010.05.021

Rall, V.L.M., Rall, R., Aragon, L.C. and Silva, M.G.D. (2005). Evaluation of three enrichment broths and five plating medium for Salmonella detection in poultry. Brazilian Journal of Microbiology, 36(2), 147-150. https://doi.org/10.1590/S151783822005000200009

Shafini, A.B., Son, R., Mahyudin, N.A., Rukayadi, Y. and Tuan Zainazor, T.C. (2017). Prevalence of Salmonella spp. in chicken and beef from retail outlets in Malaysia. International Food Research Journal, 24(1), 437-449.

Thai, T.H., Hirai, T., Lan, N.T., Shimada, A., Ngoc, P.T. and Yamaguchi, R. (2012). Antimicrobial resistance of Salmonella serovars isolated from beef at retail markets in the north Vietnam. Journal of Veterinary Medical Science, 74(9), 1163-1169. https:// doi.org/10.1292/jvms.12-0053

Thong, K.L. and Modarressi, S. (2011). Antimicrobial resistant genes associated with Salmonella from retail meats and street foods. Food Research 
International, 44(9), 2641-2646. https:// doi.org/10.1016/j.foodres.2011.05.013

Thung, T.Y., Mahyudin, N.A., Basri, D.F., Wan Mohamed Radzi, C.W.J., Nakaguchi, Y., Nishibuchi, M. and Son, R. (2016). Prevalence and antibiotic resistance of Salmonella Enteritidis and Salmonella Typhimurium in raw chicken meat at retail markets in Malaysia. Poultry Science, 95(8), 1888-1893. https://doi.org/10.3382/ps/pew144

Thung, T.Y., Son, R., Mahyudin, N.A., Rukayadi, Y., Zakaria, Z., Mazlan, N., Tan, B.H., Lee, E., Yeoh, S.L., Chin, Y.Z., Tan, C.W., Kuan, C.H., Basri, D.F. and Wan Mohamed Radzi, C.W.J. (2017). Prevalence, virulence genes and antimicrobial resistance profiles of Salmonella serovars from retail beef in Selangor, Malaysia. Frontiers in Microbiology, 8, 2697. https://doi.org/10.3389/ fmicb.2017.02697

Yang, B., Xi, M., Wang, X., Cui, S., Yue, T., Hao, H., Wang, Y., Cui, Y., Alali, W.Q., Meng, J., Walls, I., Wong, D.M. and Doyle, M.P. (2011). Prevalence of Salmonella on raw poultry at retail markets in China. Journal of Food Protection, 74(10), 1724-1728. https://doi.org/10.4315/0362-028X.JFP-11-215

Yhiler, N.Y., Bassey, E.B. and Useh, M.F. (2015). Evaluation of the performance of two selective enrichment medium and two selective plating medium for the detection of Salmonella from primary poultry production, according to ISO 6579: 2002. Open Journal of Medical Microbiology, 5(3), 128. https://doi.org/10.4236/ojmm.2015.53016

Yoke-Kqueen, C., Learn-Han, L., Noorzaleha, A.S., Son, R., Sabrina, S., Jiun-Horng, S. and Chai-Hoon, K. (2008). Characterization of multiple- antimicrobialresistant Salmonella enterica subsp. enterica isolated from indigenous vegetables and poultry in Malaysia. Letters in Applied Microbiology, 46(3), 318-324. https://doi.org/10.1111/j.1472-765X.2007.02311.x 